NBER WORKING PAPER SERIES

A NON-COMPETITIVE, EQUILIBRIUM MODEL "OF FLUCTUATIONS

Robert E. Hall

Working Paper No. 2576

NATIONAL BUREAU OF ECONOMIC RESEARCH 1050 Massachusetts Avenue

Cambridge, MA 02138

May 1988

This research was supported by the National Science Foundation and is part of the Economic Fluctuations Program of the National Bureau of Economic Research. Any opinions expressed are those of the authors and not those of the National Bureau of Economic Research. 
NBER Working Paper \#2576 May 1988

\title{
A NON-COMPETITIVE, EQUILIBRIUM MODEL OF FLUCTUATIONS
}

\begin{abstract}
$\underline{\text { ABSTRACT }}$
An equilibrium model of fluctuations has two components: an elastic labor supply schedule and a source of shifts of the labor demand schedule. In the real business cycle model, shifts of labor demand follow from vibrations in the production function. In the model of this paper, shifts of labor demand are the result of changes in preferences. Total real GNP falls when demand shifts away from goods produced by sectors with market power and toward competitive sectors. The observed cyclical stability of relative prices is consistent with such demand shifts.
\end{abstract}

Robert E. Hall

Hoover Institution

Stanford University

Stanford, California 94305 
At a very general level, macroeconomists have a common view about the basic elements of a model of fluctuations in aggregate output and employment. First, labor supply is effectively highly elastic. Real business cycle theorists posit sufficiently high intertemporal substitution in leisure that the labor supply schedule for temporary movements of the real wage is very elastic. Others, who question high intertemporal substitution, embrace theories of efficiency wages or other theories where large movements in hours of work can occur without significant changes in real wages.

The second area of basic agreement is that shifts labor demand are the basic driving force of fluctuations. In the real business cycle model, vibrations of the production function are responsible for movements of labor demand. Critics have pointed out that technical regress is not a convincing explanation of recessions. But within a one-sector model, the sources of shifts of labor demand are closely circumscribed. Any inward shift of the marginal product of labor schedule is interpretable as technical regress. Hence a two-sector model seems a more natural one to generate upward and downward shifts in labor demand. Net demand will fluctuate only if there are important asymmetries between the sectors.

The basic idea of this paper is to explore the asymmetry that results from the coexistence of monopoly and competitive sectors. The monopoly sector might be manufacturing and the competitive sector the rest of the economy. Shifts of demand generate fluctuations in total output because resources are not usually fully utilized in the monopoly 
sector whereas the competitive sector always produces at capacity.

The principal objective of this paper is to develop a model in the equilibrium style that combines elastic labor supply with the driving force of shifts in the composition of demand. In the model, contractions in aggregate output are inefficient, because they are the result of inappropriately low levels of output of the monopoly good. However; there is much more to the analysis than just the simple point that the social cost of reductions in output is higher in a non-competitive economy. That point has already been made effectively by Akerlof and Yellen (1985) and Mankiw (1985). The point here is that a competitive economy has a strong drive to full resource utlization, whereas that drive is much attenuated in a non-competitive economy. The competitor puts all his output on the market; the price-maker always has to worry about the effect of more output on the price he gets for his existing output. The analysis has some points in common with Oliver Tart's (1982) important paper.

The model in this paper relies entirely on the equilbrium mode of analysis. The preferences of the actors are clearly stated, the technology is spelled out, and the restrictions on the interactions of the actors are made plain. Subject to those restrictions, there are no opportunities for Pareto improvements. The central departure from most other equilibrium models is non-competitive behavior on the part of some sellers. These sellers perceive the true demand schedule for their products and maximize profit subject to that schedule. Of course, the resulting equilibrium is inefficient-Pareto-preferable allocations are available. However, I assume that no collective action on the part of consumers is possible to achieve 
those improved allocations.

As usual in equilibrium models, clarity and precision are achieved at considerable cost in realism. There is no more than an analogy between the recession state in this model and what actually happens in the U.S. economy in recession. But the essential elements are there, in my view. A recession involves unused resources and it is a time when no actor can improve his well-being by making a simple deal.

\section{The question of driving forces}

Any model of fluctuations has to take a stand on the sources of those fluctuations. Some commentators have made a distinction between aggregate demand and supply disturbances as driving forces in fluctuations. However, in general equilibrium, the distinction between demand and supply is not fundamental. A better distinction is among shifts in preferences, in technology, and in policy.

Recent equilibrium models, such as Prescott's (1986), have stressed technology shifts as the basic driving force of fluctuations. In models with only a single produced good, preference shocks are unattractive as a driving force because they amount to explaining recessions as periods of epidemic laziness, when the public prefers to languish at home rather than work.

The model in this paper contains shifts in both preferences and technology. The two shifts are incorporated in the model in such a way that only their product influences real allocations. In the basic 
development of the model, I will talk about the "driving variable," which is the product of the two shif: variables. Later I will discuss how preference shifts differ from technology shifts in their effects on relative prices. It turns out that preference shifts generate fluctuations that look like the ones discussed in the traditional account of variations in aggregate demand, whereas technology shifts look more like the fluctuations generated by real business cycle models.

\section{The model}

The economy has two sectors. In the first, there are worker-producers who make a good, $\mathrm{x}_{1}$, and consume both $\mathrm{x}_{1}$ and the other good, $\mathrm{x}_{2}$. There are a great many of them and they are always price-takers. They have an endowment, $z_{1}$, of good 1 . Their preferences are stated in an indirect utility function,

$$
\mathrm{V}(\mathrm{p}, \mathrm{y})=\delta^{\frac{1}{\epsilon}} \frac{\left[\frac{\mathrm{p}_{1}}{\mathrm{p}_{2}}\right]^{\epsilon-1}}{\epsilon-1}+\log \left(\frac{\mathrm{y}}{\mathrm{p}_{1}}\right)
$$

Here $p_{1}$ and $p_{2}$ are the two prices and $y$ is income. The variable $\delta$ influences the allocation of income between the two goods; it will be 
considered one of the two driving forces of fluctuations. ${ }^{1}$ The parameter $\epsilon$ controls the elasticity of demand for good 2 and is assumed to exceed one. These preferences were proposed by Burtless and Hausman (1978) in the context of labor supply. The demand for good 2 is

$$
\begin{aligned}
\mathrm{x}_{2}=\mathrm{D}\left(\mathrm{p}_{2}\right) & =-\frac{\frac{\partial \mathrm{V}}{\partial \mathrm{p}_{2}}}{\frac{\partial \mathrm{V}}{\partial \mathrm{y}}} \\
& =\left[\delta \frac{\mathrm{p}_{2}}{\mathrm{p}_{1}}\right]^{-\epsilon} \frac{\mathrm{y}}{\overline{\mathrm{p}}_{1}}
\end{aligned}
$$

I will take good 1 as numeraire and note that $y=z_{1}$, so the demand schedule for good 2 is:

$$
\mathrm{x}_{2}=\left[\frac{\delta}{\mathrm{p}_{2}}\right]^{-\epsilon} \mathrm{z}_{1}
$$

I assume the following about the technology: Sector 2 produces $\theta$ units of $\mathrm{x}_{2}$ by using 1 unit of good 1 as raw material. The variable $\theta$ is

${ }^{1}$ Readers of the earlier version of the paper should note that $\delta$ does not shift the elasticity of demand for good 2, only the level. The paper does not rest on any cyclical changes in the elasticity of demand. 
the other driving force of fluctuations. Sector 2 has a physical capacity limit, $z_{2}$. The owners of sector 2 consume only $x_{1}$, so their objective is to maximize their profit or consumption of good 1. The workers in sector 2 are incapable of working in sector 1 and they do not value their own time.

The variables $\delta$ and $\theta$ are specified so that for both, higher values are associated with greater output of good 2. I will also consider the product, $\phi=\delta \theta$, to measure their combined effect.

\section{Competition}

To find the competitive equilibrium in the model, I will examine the excess demand function for good 2:

$$
\begin{aligned}
E\left(p_{2}\right) & =D\left(p_{2}\right) & & \text { if } p_{2}<\frac{1}{\theta} \\
& =\left[D\left(\frac{1}{\theta}\right)-z_{2}, D\left(\frac{1}{\theta}\right)\right] & & \text { if } p_{2}=\frac{1}{\theta} \\
& =D\left(p_{2}\right)-z_{2} & & \text { if } p_{2}>\frac{1}{\theta}
\end{aligned}
$$

In 1.4 , price is below cost in sector 2 , so supply is zero and excess demand 
is positive. In 1.5 , price is at the point where supply from sector 2 is perfectly elastic. Excess demand is a correspondence, but there is a possibility that it includes only positive values. Finally, in 1.6 , price is sufficiently high that producers in sector 2 operate at capacity, $z_{2}$. If there was no equilibrium in 1.5 in the perfectly elastic part of the supply schedule, at price $\theta^{-1}$, there will be one at a higher price in 1.6. That price is

$$
\mathrm{p}_{2}=\delta\left[\frac{\mathrm{z}_{1}}{\mathrm{z}_{2}}\right]^{1 / \epsilon}
$$

Because this price exceeds $\theta^{-1}$, sector 2 operates at capacity:

$$
\mathrm{x}_{2}=\mathrm{z}_{2}
$$

The critical point at which sector 2 just reaches capacity is described by

$$
\mathrm{D}\left(\frac{1}{\theta}\right)=\mathrm{z}_{2}
$$

or

$$
(\delta \theta)^{-\epsilon} z_{1}=z_{2}
$$

Note that this depends just on the product, $\phi$. The critical point is 


$$
\phi^{*}=\left[\frac{\mathrm{z}_{1}}{\mathrm{z}_{2}}\right]^{1 / \epsilon}
$$

The real allocations in the economy are controlled by the composite variable $\phi$. If times are sufficiently bad that $\phi \leq \phi^{*}$, then the equilibrium occurs at a level of output below capacity and price is equal to marginal materials cost:

$$
\begin{aligned}
& \mathrm{p}_{2}=\frac{1}{\hat{\theta}} \\
& \mathrm{x}_{2}=\phi^{\epsilon} z_{1}
\end{aligned}
$$

If times are good and $\phi>\phi^{*}$, then $z_{2}$ is at its capacity level $z_{2}$, The relation between output and the driving variable $\phi$ is shown in Figure 1. Sector 2 operates at capacity except in the most unfavorable conditions. In those conditions, price falls all the way to the marginal cost of raw materials; workers earn no wages and owners carn no rents in sector 2.

\section{Monopoly}

The demand schedule facing sector 2 is

$$
\mathrm{D}\left(\mathrm{p}_{2}\right)=\left[\frac{\delta}{\mathrm{p}_{2}}\right]^{-\epsilon} \mathrm{z}_{1}
$$

In the monopoly case, sector 2 maximizes its consumption of good 1 : 


\section{Figure 1. Output under competition}

Sector 2 output

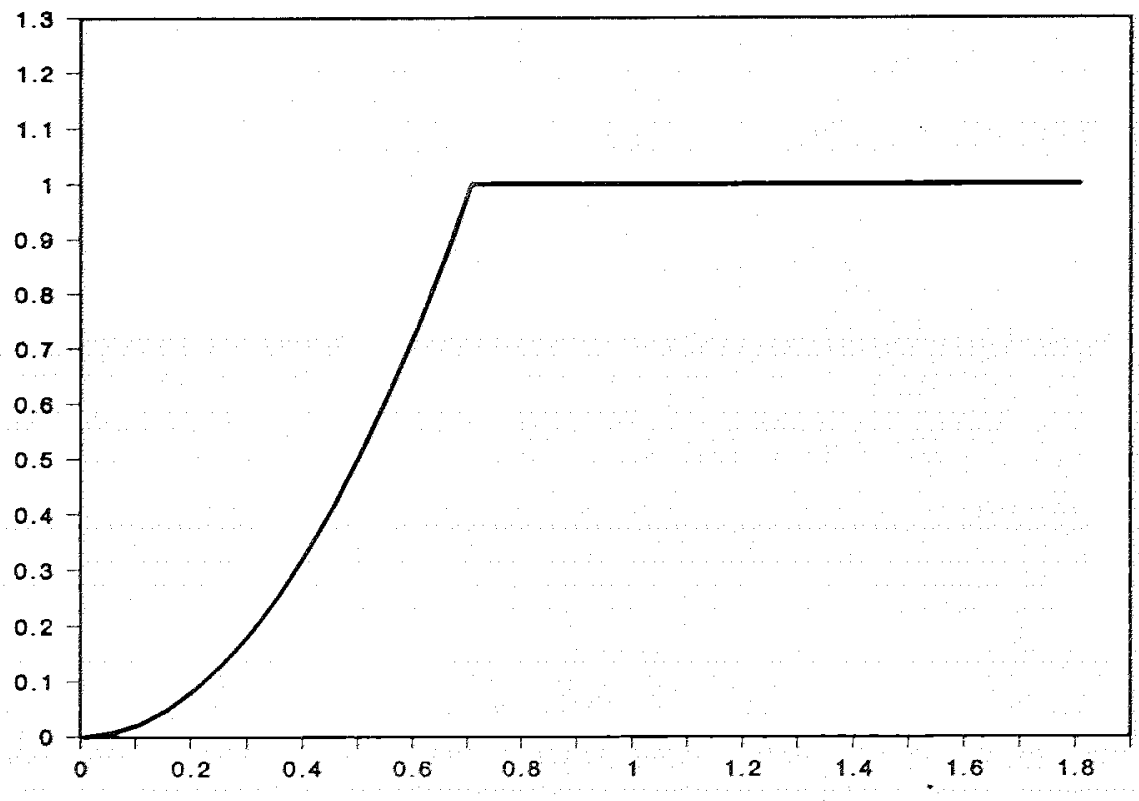

Driving variable, $\varnothing$ 


$$
\begin{aligned}
& \operatorname{Max}\left(\mathrm{p}_{2}-\frac{1}{\theta}\right) \mathrm{D}\left(\mathrm{p}_{2}\right) \\
& \text { subject to } \mathrm{D}\left(\mathrm{p}_{2}\right) \leq \mathrm{z}_{2} .
\end{aligned}
$$

At an internal maximum, the optimal price is

$$
\begin{aligned}
p_{z} & =\frac{\epsilon}{\epsilon-1} \frac{1}{\theta} \\
& =\mu \frac{1}{\theta}
\end{aligned}
$$

Here, $t$ is the markup ratio, $\epsilon /(\epsilon-1)$; price is a markup on marginal cost. Output is

$$
x_{2}=\left[\frac{\phi}{\mu}\right]^{\epsilon} z_{1}
$$

Agan, the real allocation depends just on the composite, $\phi$. A comparison of 1.17 to 1.10 shows that the critical value of the driving variable where the monopoly reaches full capacity output is $\mu \phi^{*}$.

Comparison of competition and monopoly

In the model, the capacity of sector 2 is a given value, not chosen by the economy's actors. I will compare competition and monopoly for 
the case where the capacity is the same. Of course, if the monopolist has an exclusive license for selling the second product, he would choose less than the competitive level of capacity. By the competitive level, I mean the level that would result from free entry. In comparison to the exclusive license case, my results will overstate the tendency for a monopolist to have excess capacity. On the other hand, if the monopolist does not have an exclusive license and must defend a profitable position, that defense might well involve holding at least the competitive level of capacity. Hence the comparison at equal levels of capacity is a reasonable one.

Figure 2 compares the relations between the driving variable $\phi$ and the level of output for the cases of monopoly and competition. There is a range of values of $\phi$ under which the competitive economy operates at capacity but the monopolistic economy has unused capacity. That range is

$$
\phi^{*} \leq \phi \leq \mu \phi^{*}
$$

The width of the interval is controlled in proportional terms by the markup ratio, $\mu$. If that ratio is 1.5 , for example, then the monopolistic economy has idle resources at values of $\phi$ up to 1.5 times as high as the ones where the competitive economy begins to operate at capacity. 
Figure 2. Competition and monopoly

Sector 2 output

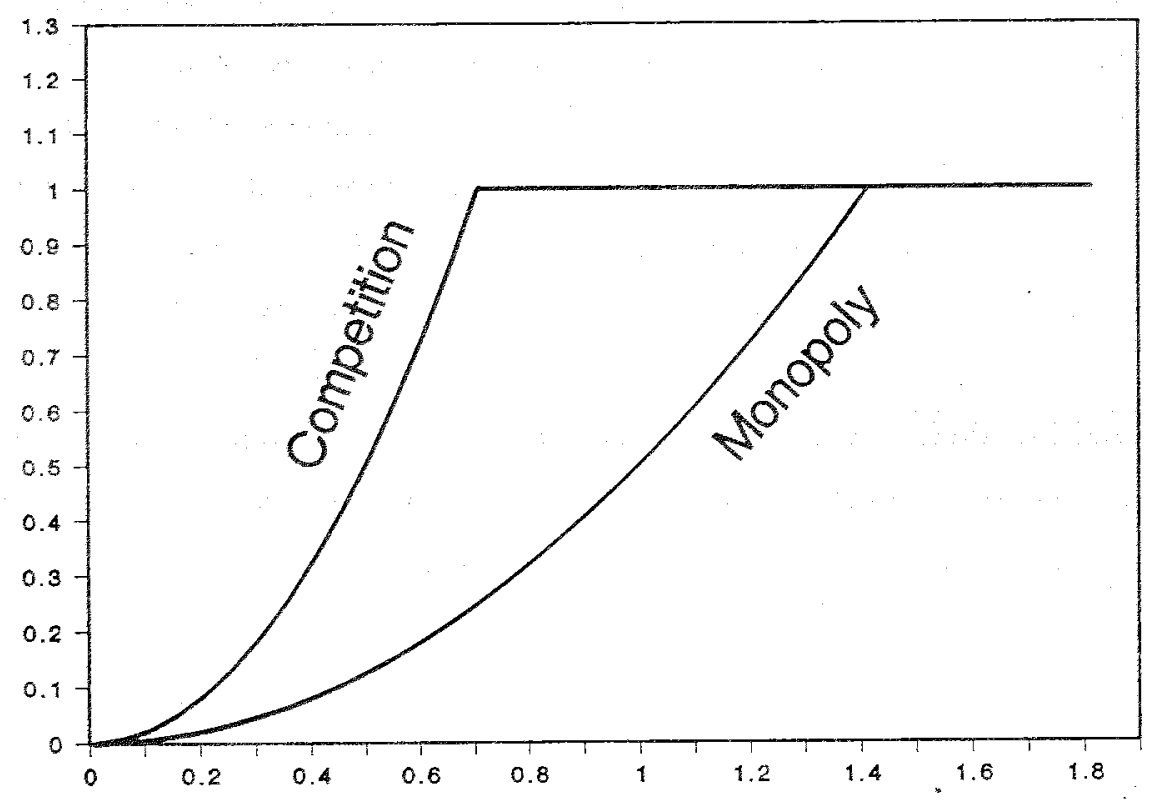

Driving variable, $\varnothing$ 


\section{Fluctuations}

Because there is no capital, the model can serve as a fluctuations model without further elaboration. In each period, there is a drawing $\phi_{t}$ from a probability distribution $F(\cdot)$ for the driving variable. The determination of output, as derived in the previous section, can be summarized for the competitive case as

$$
\begin{aligned}
& \mathrm{x}_{\mathrm{t}}=\psi_{\mathrm{c}}\left(\phi_{\mathrm{t}}\right)=\phi_{\mathrm{t}}^{\epsilon} z_{1} \quad \text { if } \phi_{\mathrm{t}}<\phi^{*} \\
& =z_{2} \quad \text { otherwise }
\end{aligned}
$$

I have dropped the subscript 2 from $x_{t}$ because the output of sector 1 never departs from its capacity, $z_{1}$. The critical value, $\phi^{*}$, for the driving variable is $\left(z_{2} / z_{1}\right)^{1 / \epsilon}$; whenever $\phi \geq \phi^{*}$, the competitive economy reaches capacity output in sector 2 .

Output for the monopolistic case is simply

$$
x_{t}=\psi_{m}\left(\phi_{t}\right)=\psi_{c}\left(\frac{1}{\mu} \phi_{t}\right)
$$

In both cases, the price of good 2 can be obtained from the inverse of the demand function:

$$
\mathrm{p}_{\mathrm{t}}=\delta\left[\frac{z_{1}}{\mathrm{x}_{\mathrm{t}}}\right]^{1 / \epsilon}
$$


Again, I have dropped the subscript 2.

The following discussion will make the assumption that there is some chance that $\phi_{\mathrm{t}}$ will be below the level, $\mu \phi^{*}$, and so in the region where sector 2 operates below capacity and monopoly power affects the allocation. That assumption can be expressed as $\mathrm{F}\left(\mu \phi^{*}\right)>0$. Then there are four ways to express the general conclusion that the monopolistic economy is more vulnerable to episodes of unused capacity:

1. The expected value of $\mathrm{x}_{\mathrm{t}}$ is lover under monopoly than under competition.

2. The monopolistic economy has unused capacity a larger fraction of the the; the probability of slack under monopoly is $F\left(\mu \phi^{*}\right)$, which exceds the probability of slack under competition, $w^{*}\left(\phi^{*}\right)$.

3. If $F\left(\phi^{*}\right)=0$, then the competitive economy will always operate at capacity, whereas the monopolistic econony will have slack whenever $\phi_{t}$ $<\mu \phi^{*}$

4. Under conditions when both economies would have slack $\left(\phi_{\mathrm{t}}<\phi^{*}\right)$, the monopolistic economy always has more slack: $\psi_{\mathrm{m}}<\psi_{\mathrm{c}}$.

As Figure 2 demonstrates, is is not just that the ineficiency associated with monopoly power has the general effect of reducing the output of sector 2 in equillibim. Rather, the impact is concentrated in 
bad times. The reason for this is simple. Once sector 2 reaches its capacity, monopoly power has no effect on its output or price. The adverse effects of monopoly occur only when output is below capacity; this happens only in bad times.

\section{Aggregate output}

The output of sector 1 is always equal to its endowment $z_{1}$. Excess capacity cannot occur as long as good 1 is valued positively; that is, $\mathrm{p}$ is finite. Only the output of sector 2 changes over time. Aggregate output could be measured as real GNP,

$$
y=z_{1}-\frac{1}{\theta} x_{2}+p_{0} x_{2}
$$

The quantity $z_{1}-\frac{1}{\theta} x_{2}$ is deliveries of good 1 to final demand and $p_{0} x_{2}$ is deliveries of good 2 to final demand, valued at a base year price $p_{0}$. Real GNP can also be expressed as the sum of value added in the two sectors:

$$
y=z_{1}+\left(p_{0}-\frac{1}{\theta}\right) x_{2}
$$

As long as the base-year price, $\mathrm{p}_{0}$, exceeds marginal materials, cost, $\frac{1}{\theta}$, real GNP will be positively related to sector 2 output.

The preference shift, $\delta$, which only changes the composition of 
demand at the level of the individual, affects the level of output in the aggregate. The influence is much greater in the case of monopoly, because $p_{0}$ will exceed $\theta^{-1}$ by a wider margin in that case. The technology shift, $\theta$, operates in the same way by influencing the level of $x_{2}$ and also increases real GNP by reducing the imput requirement, $\theta^{-1} x_{2}$, which is a charge against real GNP.

I conclude that the variations in the output of sector 2 will give rise to fluctuations in real GNP. To put it a different way, fluctuations in real GNP will be seen as fluctuations in the sum of the value added in a cyclically stable sector (sector 1 ) and cyclically sensitive sector (sector 2).

\section{Comparison of shifts in preferences and in technology}

One of the salient characteristics of fuctuations in modern economies is the insensitivity of relative prices and wages to slack conditions. Traditional macroeconomic thinking has made price-wage rigidity a starting point for explanations of fluctuations. Other models, including this one, derive price rigidity from assumptions about the underlying characteristics of the economy. In this mode?, there is no distinction between workers and owners, so there is no way to measure wage rigidity. However, it is possible to examine the cyclical movements of the relative price.

The movements of the relative price are quite different under preference shifts from those under technology shifts. Comovements of 
relative price and relative cuantity are one of the ways to deternine the relative importance of the two driving forces In competition, a shift of preferences toward good 2 will raise its relative price. On the other hand, an improvement in the technology in sector 2 will lower the relative price. In monopoly, the second statement remains true, but the first may fail. In the region of constant marginal cost, with output below capacity in sector 2 , the behavior of the monopolist's price depends on the behavior of the elasticity of demand. The relative price can rise or fall when preferences shift, depending on what happens to the elasticity.

\section{Shifts in preferences}

Figure 3 plots the relative price of good 2 against the value of the preference shift, $\delta$, for both competition and monopoly. The plot assumes a constant value of $\theta$ of 1 . Under competition, the price is constant at $\theta^{-1}$ $=1$ up to capacity. Above that, the relative price serves its function of allocating the increasingly scarce fixed capacity of sector 2. Under monopoly, however, the relative price is constant over a rnuch wider range. When output reaches capacity, monopoly no longer has any effect. Price is set purely by the competitive principle of allocating scarce capacity.

If the preference variable $\delta$ varies in a region mostly below the capacity point, $\mu^{*} / 0$, the relation between output and price will be essentially flat. The relative price will appear to be rigid. But the rigidity is the result of monopoly power with constant demand elasticisy, not a 
Figure 3 . Price with preference shift

Sector 2 price

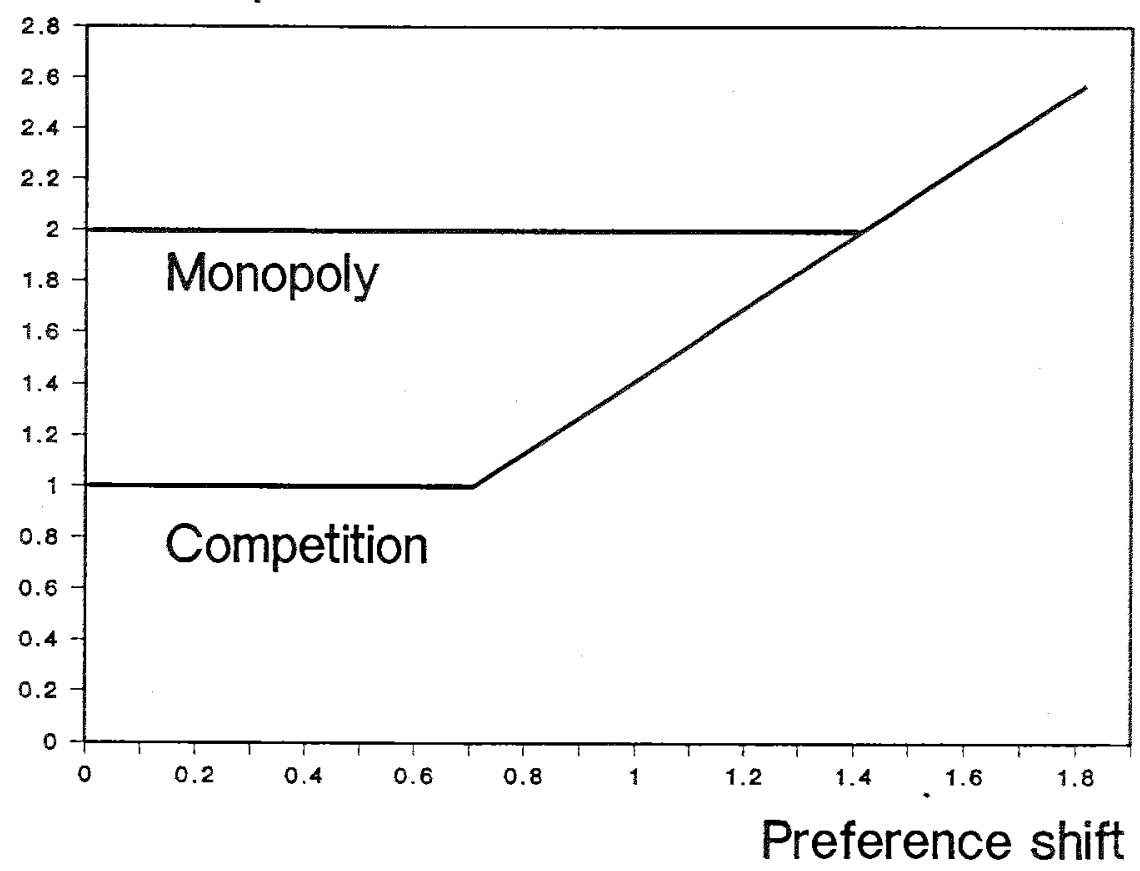


direct assumption of the model. If the elasticity of demand rises when the level of demand rises, then the relative price will move inversely with output, up to capacity output.

\section{Shifts in technology}

It is an unambiguous implication of both competition and monopoly that improvements in the productivity of sector 2 lower the relative price of good 2. Figure 4 illustrates the relationship between the relative price and the driving variable, when all the variations in the driving variable come from the technology variable $\theta$ and the preference variable 6 is held constant at 2 . For both competition and monopoly, the relative price declines in the region where output is below capacity. Above capacity, marginal cost is irrelevant; price is at the level needed to ration scarce camacity. Hence, the price remains constant as $\theta$ rises beyond the full-capacity point. Improvements in technology are captured as higher earnings by producers in that region.

One of the interesting features of Figure 4 is that price rigidity is more pronounced in competition than in monopoly. As I have stressed earlier, the monopoly is more likely to operate below capacity. Below capacity, price is negatively related to the productivity variable and negatively related to output. 
Figure 4. Price with technology shift

Sector 2 price

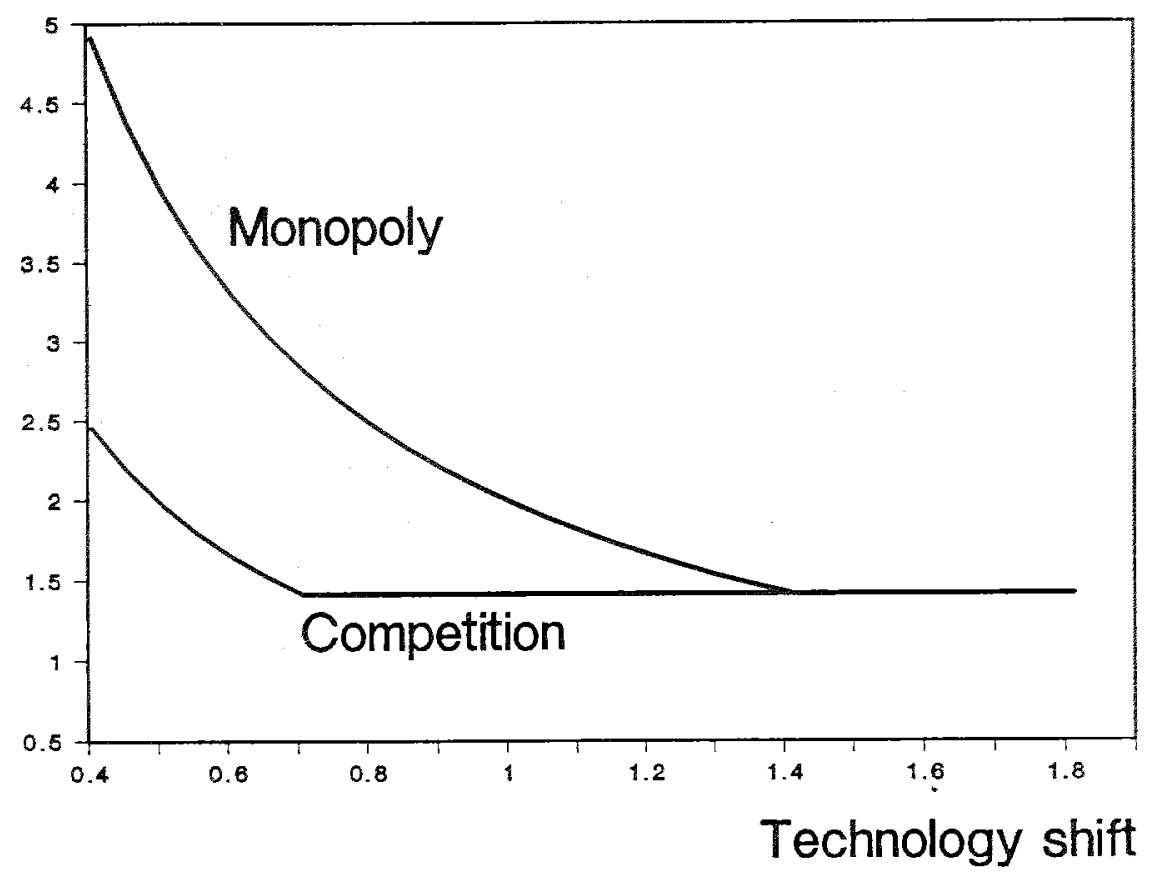




\section{Conclusions from relative price movements}

I believe that it is a reasonable stylized fact of business cycles that there are no robust and important fluctuations in relative prices over the cycle. "Cyclically-sensitive" prices are hard to find and are limited to quantitatively unimportant sectors such as scrap metal. There is evidence that in deep, prolonged contractions, the prices of competitively-supplied goods tend to fall more than those of monopoly or oligopoly goods (Stigler (1947)).

The stylized fact of roughly constant relative prices is consistent with the preference-shift story of Figure 3 , where the relative price of sector 2 is roughly independent of output. It is inconsistent with the technology-shift story of Figure 4, which would call for a declining price for an expanding sector.

4. Is a recession in the model anything like a recession in a modern economy?

The remarks in the previous section make it clear that the nodel fits the stylized fact of relative price stability when fluctuations are driven by preference shifts, not by technology shifts. Is it plausible that shifts of 
preferences among categories of goods are an important driving force in a modern economy? In the model as stated, a shift favoring a competitive good as against a monopoly good causes a recession. More generally, a shift away from a sector which has excess capacity toward one that is operating at full capacity will cause a recession. Market power is important in the general case because it is unlikely that a competitive sector would ever operate below capacity.

In addition to pure shifts in underlying preferences, it is appropriate to include changes in household technology in the interpretation of the driving variable, $\delta$. Under one interpretation, $\delta$, could be a time cost of purchasing good 1 in relation to good 2. An increase in the inconvenience or effort required to make a purchase of good 2 would be equivalent to a decline in $\delta$ and would set in motion the decline in total output described by the model.

In a more general model, $\delta$ could include other costs. In particular, if the monopoly good is a durable good frequently purchased on credit, the $\delta$ could include the influence of credit rationing (Stiglitz and Weiss (1981)). Or, again for durables, $\delta$ could capture the benefits to delaying durables purchases in times of increased uncertainty as discussed by Bernanke (1983).

The model as stated contains no explanation for monetary nonneutralities. However, if monetary events can generate changes in $\delta$ through credit rationing, uncertainty, or other mechanisms, then the model of this paper can explain the propagation of monetary shocks into fluctuations in real GNP. 


\section{Labor supply assumptions}

A second important question is whether the labor supply assumptions for sector 2 in the model have any analogy in a real economy. There is no contribution to marginal cost from the value of workers' time. Or, to put is a different way, labor supply is perfectly elastic. The model rests on elastic labor supply just as the real business cycle and wagerigidity models do. The question is whether this form of the elastic labor supply assumption is more realistic than the other forms.

The hypothesis of perfectly-elastic labor supply at zero wage has beex widely accepted as part of the theory of labor hoarding. In times of weak demand, the firm retains workers on the payroll who are not fully occupied. Their services are available to the firm for free. The firm, not the worker, has the perfectly elastic labor supply, but the resulting allocation of labor is as described in the model. Garber (1986) has found empirical support tor the labor-hoarding proposition. He tests and accepts the hypothesis that prices, output, and employment are unaffected by changes in wages paid to workers during periods of labor hoarding. In other words, the wage does not allocate labor during downturns, according to Garber's evidence. Firms buy a block of their workers' time and then allocate it as they please. The implicit cost of labor up to the time commitment is zero, and the assumption of this paper is appropriate.

A related defense of the assumption is that workers have the standard textbook labor supply schedule - a vertical line at full-time work, 
connected to the origin by a perfectly elastic segment at wage zero. In addition, the possibility of supplying labor to a different sector, which would make the labor supply schedule for sector 2 be different from the labor supply schedule to the market, is foreclosed. High mobility costs would be the best explanation for the irrelevance of alternative employment opportunities. Hall (1987) shows that workers will be inhibited from moving to other sectors during temporary downturns under reasonable assumptions about costs and preferences .

The conclusions of the model would not be changed if workers put a value on their time, as long as the marginal value did not vary with the amount of work. That is, it is the property of highly elastic supply, not the zero marginal value of time, that is critical in this and other equilibrium models of employment fluctuations. As Rogerson (1988) and Hansen (1985) have noted, highly elastic labor supply can be the result of aggregation over individuals who are indifferent between working full days and not working at all. The indifference could arise from fixed costs of going to work. In Hall (1987), I show that it is extremely unlikely that workers could be on the horizontal parts of their labor supply schedules a large fraction of the time. However, fixed costs can contribute a perfectly elastic segment to the labor supply schedule, where the flat part of the schedule begins for hours of work somewhat below normal.

If the perfectly elastic part of the labor supply schedule occurs at a positive wage, the model of this paper can easily be modified to accommodate that feature by absorbing the level of the wage into $\theta^{-1}$.

Figure 5 compares the labor supply assumptions of the four types of fluctuations models. The real business cycle model makes the explicit 
Figure 5. Alternative Labor Supply

Schedules

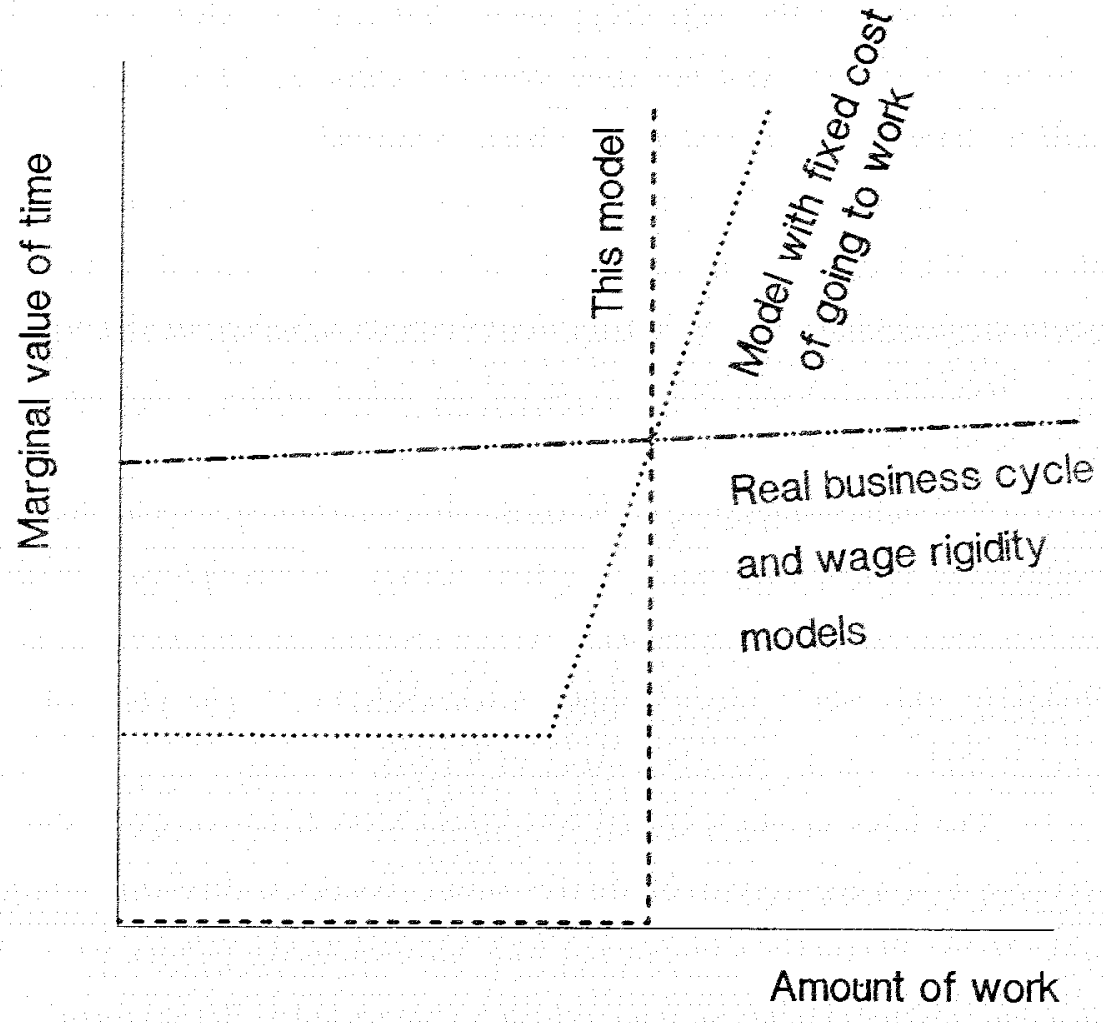


assumption that labor supply is highly elastic. A temporary reduction in the real wage brings a large reduction in work effort because the worker is virtually indifferent to the scheduling of work. The shadow value of the worker's time is set by the total amount of work performed over the lifetime. Whenever the wage drops below that shadow value, it is a good time to stop working and use time for other purposes. The work can be made up later, when the real wage is back to normal.

In the wage rigidity model, the worker agrees to work as much as asked by the employer (up to some limit) at a predetermined wage. The agreement supplants the underlying labor supply schedule of the worker. The allocation of work proceeds as if the labor supply schedule were perfectly elastic.

The labor supply of this model is a reverse $L$. The level of employment is frequently along the flat, perfectly elastic portion because the firm frequently has a marginal revenue product of labor equal to zero. Obviously, this would rarely happen in competition. The point of this paper is that it can frequently happen with market power.

The labor supply schedule in a model with fixed costs of going to work has a flat segment at a positive wage. Again, a firm with market power facing fluctuations in demand may have extensive periods when the marginal revenue product of labor schedule intersects the flat segment. 


\section{Concluding remarks}

One of the unique responsibilities of the macroeconomist is to identify the driving forces of economic fluctuations. The real business cycle model considers economy-wide fluctuations in productivity as the major driving force. Critics have pointed out that technical regress is a questionable cause of recessions, but have not been active in identifying alternative driving forces. In a one-sector model, preference shifts are not a plausible driving force, because the only preference shift that could cause a recession would be a shift away from goods consumption and toward leisure consumption.. Labeling a recession a period of epidemic laziness is unattractive to all schools of macrocconomics.

A two-sector model enriches the set of possible driving forces. Productivity could shift in favor of one sector from time to time, for example. However, such shifts must be accompanied by corresponding changes in relative prices. Because cyclical changes in relative prices are weak, productivity shifts again seem unattractive as an important driving force at business-cycle frequencies. On the other hand, shifts in preferences from one sector to another are a more promising type of driving force, if there is enough asymmetry between the two sectors. Monopoly in one sector and competition in the other provides the necessary asymmetry. If the competitive sector always operates at capacity, but the monopoly sector sometimes operates below capacity, preference shifts will cause changes in aggregate real GNP but not in the relative price. 


\section{References}

George A. Akerlof and Janet L. Yellen, "A Near-Rational Model of the Business Cycle, with Wage and Price Inertia," Quarterly Journal of Economics 100:823-838, Supplement 1985

Ben S. Bernanke, "Irreversibility, Uncertainty, and Cyclical Investment," Quarterly Journal of Economics 98: 85-196, February 1983

Gary Burtless and Jerry A. Hausman, "The Effect of Taxation on Labor Supply: Evaluating the Gary Negative Income Tax Experiment," Journal of Political Economy 86:1103-1130, December 1978.

Steven Garber, "The Reserve-Labor Hypothesis, Short-Run Pricing Theories and the Employment-Output Relationship," Carnegie-Mellon University, July 1986

Robert E. Hall, "The Volatility of Employment with Fixed Costs of Going to Work," Stanford, June 1987

Gary D. Hansen, "Indivisible Labor and the Business Cycle," Journal of Monetary Economics 16:309-327, 1985

Oliver Hart, "A Model of Imperfect Competition with Keynesian 
Features," Quarterly Journal of Economics 97: 109-138, February 1982

N. Gregory Mankiw, "Small Menu Costs and Large Business Cycles: A Macroeconomic Model of Monopoly," Quarterly Journal of Economics 100: 529-538, May 1985

Edward C. Prescott, "Theory ahead of Business Cycle Measurement," in Karl Brunner and Allan Meltzer (eds.) Real Business Cycles, Real Exchange Rates and Actual Policies, Volume 25 in the Carnegie-Rochester Conference Series on Public Policy, North-Holland, 1986, pp. 11-44.

Richard Rogerson, "Indivisible Labor, Lotteries, and Equilibrium," Journal of Monetary Economics 21:3-16, January 1988

George Stigler, "The Kinky Oligopoly Demand Curve and Rigid Prices," Journal of Political Economy 55, October 1947, reprinted in George Stigler, The Organization of Industry (Homewood, Illinois: Richard D. Irwin), $1968, \mathrm{pp} \ldots 208-234$

Joseph E. Stiglitz and Andrew Weiss, "Credit Rationing in Markets with Imperfect Information," American Economic Review 71: 393-410, June 1981 